\title{
José Honório Rodrigues: a obra inacabada
}

\author{
Carlos Guilherme Mota
}

A publicação póstuma do segundo volume da História da História do Brasil, do historiador carioca José Honório Rodrigues (1913-1987), dá continuidade ao seu esforço notável de sistematização e avaliação da historiografia brasileira, lamentavelmente interrompido com seu falecimento na madrugada de 6 de abril de 1987. Com ele, uma visão generosa e empenhada da história do Brasil desaparece. Coube a sua mulher e permanente colaboradora, a historiadora Lêda Boechat Rodrigues - autora, entre outras obras, de uma excelente História do Supremo Tribunal Federal -, cuidar da edição final dos dois tomos, que foi publicada pela Companhia Editora Nacional, sob a direção de Jorge Yunes, com apoio do Instituto Nacional do Livro. Iniciativa inestimável - que esperamos tenha prosseguimento, pois a obra honoriana é vasta e muito resta a vir à luz - num país em que livros desta importância não têm mercado assegurado a curto prazo.

Autor de quase trinta livros, além de inúmeros ensaios e artigos sobre nossa história e sobre a historiografia contemporânea, José Honório projetava algo que seria sua obra maior sobre a historiografia brasileira, de que $\epsilon$ hoje a figura mais eminente $e$ produtiva. A Historia da História do Brasil estava planejada para seis volumes, dos quais já publicara, em 1979, o primeiro, Historiografia Colonial, seguido agora do volume II, dois tomos, sobre a Historiografia Conservadora (1988) e sobre $A$ Metafísica do Latifúndio: $o$ ultra-reacionário Oliveira Viana (1988), que comentaremos adiante. Os demais volumes versariam sobre $A$ Historiografia Liberal, A Historiografia Católica, Republicana e Positivista, Do Realismo ao Socialismo e o último sobre a Historiografia Estrangeira sobre o Brasil. Esse o grande projeto de José Honório, iniciado em 1944 após seu retorno dos Estados Unidos, e que se desdobrava em três vertentes maiores: o da Teoria da História do Brasil, o da Pesquisa Histórica no Brasil e o inacabado História da História do Brasil. Paralelamente, recordem-se seus livros de polemista, Conciliação e Reforma no Brasil (1965), Aspirações Nacionais (1963) e História Combatente (1982), além do trabalho incansável de pesquisa erudita e de publicação, como a que realizou da obra de Capistrano de Abreu - de quem descendia intelectualmente - ou dos Documentos Históricos da Biblioteca Nacional, ou ainda, dos numerosos prefácios que escreveu apresentando estudos dos viajantes e historiadores, ou catálogos e documentos como Os Holandeses no Brasil, as Atas do Conselho de Estado ou $O$ Parlamento e a Evolução Nacional. Talvez nảo exista na historiografia brasileira alguém que tenha desempenhado com tanto conhecimento e ardor o "métier d'historien" em todas essas facetas. Empolgava-se com o que escrevia, com o que falava, com o que pesquisava, julgando e qualificando as informações e os personagens envolvidos como se fossem seus contemporâneos. Assim, Frei Caneca e seu algoz Pedro I, por exemplo, são devidamente recolocados no contexto sócio-político da época, em frases contundentes e diretas, da mesma forma que ao historiador Varnhagen 
reserva Jose Honório classificação dura, não passando para ele de um áulico - o que aliás era. Honório alinhava-se ao lado dos vencidos, denunciando os mitos da história "cordial" do Brasil numa época em que era difícil fazê-lo (hoje $\epsilon$ moda), analisando a vitória permanente da contra-revolução ("há um esboço de revolução, vem a contra-revolução que reprime e extrai algumas poucas teses do movimento inovador $e$ as aplica a seu modo, conciliando e esvaziando o conteúdo histórico", disse-me certa vez numa mesa-redonda organizada pelo Jomal da Tarde) ao longo da nossa história, revelando a história cruenta e criticando os sipaios brasileiros, que têm os pés no País, mas o coração em outro lugar.

Nos dois tomos do volume II, Jose Honório apresenta a historiografia conservadora de modo a se visualizarem as diferentes facetas do pensamento conservador no Brasil. "Somos por tradiçẳo portuguesa um povo extremamente conservador", diz Honório, justificandó sua atenção na problemática. No tơmo 1 , focaliza a historiografia conservadora, a monarquista e a linha reacionária e contra-revolucionária. No tomo 2 , concentra a atenção no pensamento de Oliveira Viana, percoirrendo sua extensa obra e indicando sua presença no pensamento político brasileiro contemporâneo, particularmente em Golbery do Couto e Silva, ideólogo do movimento de 1964.

Rico de informaçōes e sugestōes, em A Historiografia Conservadora Honório conceitua a interpretação tradicionalista de história, localizando-a no contexto brasileiro, ou melhor, na definição do processo histórico do País recém-independente. Embora se possa discutir a simplificação dessas teorias e a divisão em três vertentes (historiografia conservadora, monarquista e reacionária ou contra-revolucionária), pois em alguns casos se sobrepóem, em outros conflitam, há neste tomo 1 análises que valem o livro. Está-se longe da lição de Karl Mannheim para a compreensão do conservadorismo, no sentido de que nâo há em José Honório um esforço para explicar as condiçōes em que se produzem (e reproduzem) no Brasil as formas de pensamento ligados à ordem estabelecida, ou francamente regressistas e que ocorrem de tempos

\section{JOSÉ HONÓRIO RODRIGUES}

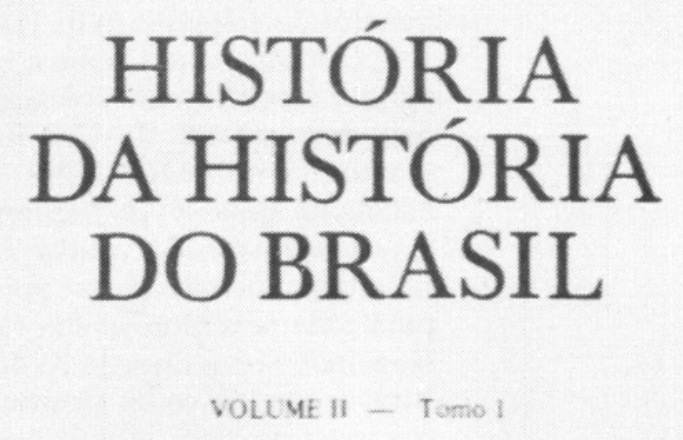

A Historiografia Conservadora

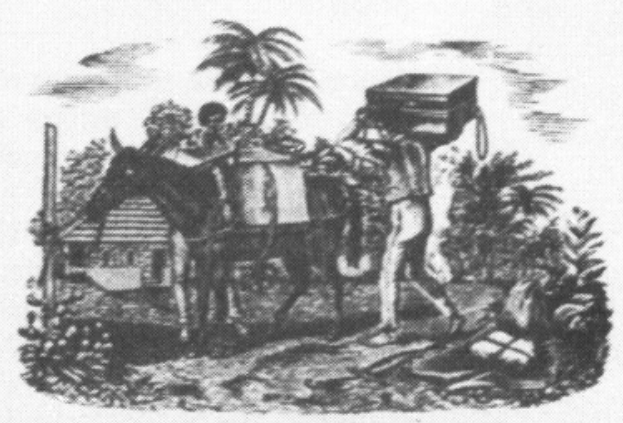

COMPANHIA EDITORA NACIONAL 
em tempos, como hoje. Não obstante, na apresentação do capítulo I já há indicaçóes da postura do historiógrafo de combate. $O$ texto $e$ desigual, revelador da impaciência do autor, mas o resultado é correto na avaliação do conservadorismo historiográfico ("O Brasil é um país atrasado, sempre foi", dizia Caio Prado há não muito tempo), e 0 ataque desferido a Varnhagen e outros, disso, é exemplo. Particularmente interessante, a comparação deste com o inglês Southey, o historiador que "condenou o despotismo, o sistema de vigilância policial, a falta de segurança do cidadão, a falta de instrução e imprensa, dos monopólios, os agravos que tanto frearam o curso livre da história nacional".

Aí se encontra a pedra angular da teoria da história do Brasil de Honório. Todos seus atos, pesquisas e ensaios ligam-se à procura da história nacional, mas não em perspectiva simplista ou conservadora. A chamada Questão Nacional, a irresolução do Brasil, enquanto país moderno e auto-suficiente, assume, em sua visão de história, importância central. Daí dedicar-se febrilmente enquanto historiador a temas decisivos como a Independência: Revolução e Contra-Revolução, obra em cinco volumes, ou sobre à vida parlamentar ou ainda propósito da política externa brasileira (participou, aliás, da criação da revista Politica Externa

Independente). Enquanto editor de documentos, procurava sempre organizar coleçôes que contribuíssem para a elaboração de nossa história social e polftica, e os melhores exemplos são os Documentos Históricos (1946-1955) e os Anais da Biblioteca Nacional (1948-1963), em geral sobre movimentos ligados à emancipação. Enquanto historiógrafo, sempre procurava os elementos intelectuais e políticos que colaborariam para a formação de uma "consciência nacional" - para ele inextrincavelmente vinculada a uma consciência social. Liberal, não via o povo numa perspectiva populista, como muitos de seus companheiros de geração, eventualmente mais à esquerda ("somos por tradição portuguesa um povo - incluo aqui todas as classes em conjunto extremamente conservador'). Enquanto conferencista e polemista, ressaltem-se suas conferências na Escola Superior de Guerra, que redundaram nos livros Aspiraçōes Nacionais e o célebre Conciliação e Reforma (livros com várias reedições), Época em que julgou possível falar aos militares (na verdade, seus intercâmbios

bibliográficos com figuras como o então coronel Golbery do Couto e Silva ampliaram suas leituras, que passaram a incluir, ainda nos anos 50 , Hannah Arendt e David Riesman..., mas em geral foi um cético quanto a eles, que o procuravam bastante para subsidios historicos). Ou palestras a estudantes como aquela nos idos de 1964 (Vida e História), no cine Gazeta, com apresentação de Sérgio Buarque, Davi Lerer e minha, em que a avenida Paulista foi cercada por policiais. Jose Honório inflamava-se e transfundia seu entusiasmo aos mais novos.

Suas opiniōes sempre foram diretas e incisivas, ora lembrando que Frei Caneca foi o maior pensador político do século XIX, ora alertando contra os transbordamentos do militarismo antinacional: "todo absolutismo é uma forma de colonialismo". Ou: "Se o Tenentismo näo foi bom para o pars, o generalismo foi péssimo". Em qualquer hipótese, a "Questão Nacional' era sua paixão, 0 historiador com seus instrumentos ajudando a construir um País moderno, aberto ao mundo, porem independente. Os sipaios, os cabeças-de-ponte, os empresários, militares ou intelectuais alienados, os ambivalentes, provocavam seu desprezo, quando não, ira.

Nos referidos dois tomos, Honório revela, em seu contundente estilo, os limites ideológicos e historiograficos de figuras como Joaquim Manuel de Macedo, liberal que impós à juventude uma conservadora visão da história do Brasil. Critica acerbamente esse liberalismo paradoxal e extremamente conservador, que 
defendia a escravidão negra, distanciado do liberalismo mais radical de 1817, 1824 e 1848, e que volta "à se rédefinir nos liberais reformistas dos monarquistas representados pelos dois Nabucos, ou pelos republicanos e federalistas". Macedo "escreveu um péssimo livro didático", "era um professor medíocre", eis um julgamento severo proferido num tom que a crítica contemporânea já não sabe ou não ousa mais fazer.

No percurso, o leitor encontrará análises e observaçōes vigorosas sobre o conservador-monarquista Bernardo Pereira de Vasconcelos, expressão de um grupo-geração resistente às insurreições populares; Clemente Pereira, liberal na Independência e conservador depois; Afonso Celso, o visconde de Ouro Preto, numa perspectiva nova, inclusive crítico da espoliação inglesa; e sobretudo de Eduardo Prado (1860-1901), a quem dedica a melhor e mais longa análise. "Sabia bem todas as coisas que sabia", segundo Machado de Assis. Sua geração, seus livros, sua colaboração na revista de Eça de Queirós, a luta contra a República, seu antijacobinismo e suas pesquisas eruditas são visitadas por José Honório com razoável distanciamento crítico, sobretudo para um jacobino como era. No capítulo III, dedica-se ao pensamento reacionário, e em que focaliza, entre outros e com destaque, José da Silva Lisboa, o visconde de Cairu. $O$ reacionarismo ideológico surge, segundo pensa, como reaçāo à Revolução Francesa, e marca figuras como o bispo ilustrado Azeredo Coutinho, Cairu e Oliveira Viana "este, horrorizado com as constantes rebeliōes brasileiras que encheram a República desde a fundaçāo até sua época". No caso de Cairu, o historiografo oferece, em cinqüenta páginas, excelente exercício de reconstrução do pensamento histórico desse "combatente do predomínio inglês no Brasil", revendo sua formação e repassando as leituras críticas contemporâneas de Oliveira Lima, Buarque, San Tiago Dantas, em contraposição ao entusiasmado Alceu de Amoroso Lima. No exame da extrema direita, desfere golpes em Helio Viana e Gustavo Barroso, "dois pequenos reacionários", muito "longe de seguirem uma linha reacionária coerente e lógica como a de Oliveira Viana".

Ao "ultra-reacionário" Oliveira Viana dedica um tomo especial sob o título instigante de "A Metafísica do Latifúndio". Embora a moderna historiografia contemporânea venha se desembaraçando decididamente das teorias de Viana, năo se pode negar sua importância para o grupo-geração Caio Prado-Buarque-Freyre. Caio Prado, em seu revolucionário Evolução Política do Brasil (1933), critica a todos, mas ressalva a importância das análises de Viana ja na primeira nota; Buarque polemiza abertamente com ele em Raizes do Brasil e Freyre cria seu espaço na interlocução com Viana, à direita, e à esquerda com Astrojildo Pereira, embora incorporando muito do primeiro.

Ao dedicar um volume especial a Oliveira Viana, que tanto marcou o pensamento autoritario brasileiro contemporâneo, José Honório, comentando um medíocre pensador francês que estimulou o ideologo racista, não deixa por menos e oferece excelente exercício de seu áspero estilo, que tanta falta fará para a elaboração de uma historiografia brasileira autêntica: " A diferença essencial entre Le Play e Oliveira Viana $€$ que o primeiro não mudou nada no mundo da organização política e social, enquanto Oliveira Viana encontrou os Golbery, que por sua meia-ciência se deixaram empolgar pelo ultrapassado e ultra-reacionário sócio-psico-antropólogo-gébgrafo pensador, que não encontrou no meio civil uma única expressão intelectual que o seguisse".

Carlos Guilherme Mota é professor-titular de História Contemporânea da FFLCH/USP e membro do Conselho Diretor do IEA. 